\title{
O Olhar de Crianças Atendidas em Instituição Pública de Saúde Sobre o Psicoterapeuta
}

\author{
Rodrigo Gabbi Polli \\ Universidade Federal do Rio Grande do Sul \\ Dorian Mônica Arpini \\ Universidade Federal de Santa Maria
}

\begin{abstract}
RESUMO
O estudo objetivou investigar a forma como crianças que estavam em atendimento psicológico na rede básica de saúde representam o seu terapeuta. Realizou-se um estudo qualitativo com a aplicação da técnica do desenho-estória. Oito crianças participaram da pesquisa. Foi solicitado a elas que realizassem uma sequência de três desenhos-estórias. A análise dos dados foi feita por meio de análise de conteúdo. Os resultados evidenciaram que as crianças têm uma representação de psicoterapeuta enquanto alguém que brinca e conversa com elas. Além disso, para que o processo terapêutico se dê, foi valorizada a capacidade do profissional de prover um ambiente confiável e amparador, no qual a criança se sinta segura para apresentar suas questões, sendo destacado o holding recebido ao longo da terapia.

Palavras-chave: Psicoterapia da criança; saúde pública; crianças.
\end{abstract}

\begin{abstract}
The perspective of the children treated at primary health care unit about psychotherapist

This study aimed to investigate how children who were under psychological care, in basic health institution, represent their therapist. A qualitative study was carried out, using the draw and tell a story procedures. Eight children participated in this study. Children were asked to perform a sequence of three drawing-stories. The data analysis was performed using content analysis. The results showed that children have a representation of the psychotherapist as someone who plays and talks with them. Moreover, in order to make the therapeutic process happen, the ability of the professional to provide a reliable and supportive environment was valued. In this place, the child feels safe to bring up their issues, highlighting the holding received during the treatment.
\end{abstract}

Keywords: Child psychotherapy; public health; children.

A ampliação da oferta de serviços de Psicologia no campo de saúde mental direcionada a toda a população denuncia o reconhecimento da importância do sofrimento psíquico como um dos fatores que devem ser considerados quando o foco é o bem-estar de indivíduos, grupos e comunidades (Bezerra, 1987). A inserção da Psicologia - incluindo o fazer da Psicologia Clínica - em realidades novas e voltadas a outras populações convoca profissionais e estudiosos da área a pensar sobre as necessárias adaptações e modificações que toda realocação de uma prática implica (Boarati, Sei, \& Arruda, 2009; Costa, Mombelli, \& Marcon, 2009; Finkel, 2009; Menezes, López, \& Delvan, 2010; Sei \& Cintra, 2013). Contudo, alguns autores salientam certa inadequação dos dispositivos terapêuticos quando da inserção da clínica psicológica, sobretudo daquela de orientação psicanalítica, em unidades básicas de saúde, ambulatórios ou qualquer outro serviço que em alguma medida se diferencia do consultório particular (Bezerra, 1987; Figueiredo, 1997; Ropa \& Duarte, 1985; Seixas, 2011). Tal limitação do modelo de escuta e intervenção da prática psicoterápica em face de determinados grupos geralmente diz respeito a uma diferença no sistema linguístico ou a uma incompreensão da cultura daquela população, o que pode produzir serviços descolados da realidade e atendimentos, por sua vez, ineficazes (Meyer \& Berlinck, 2011; Ropa \& Duarte, 1985). Diante disso, o presente artigo objetivou refletir sobre a prática do psicólogo clínico conforme representada por crianças que estavam em atendimento psicológico na rede básica de saúde.

\section{A psicoterapia de crianças}

Klein $(1975,1997)$ nos mostra que, a partir das ob- 
servações psicanalíticas, a infância deixa de ser vista como uma fase "tranquila", livre de conflitos. Seja devido aos impulsos sexuais, aos desapontamentos pelas falhas do ambiente e/ou aos sentimentos de culpa, as crianças - mesmo as que estão na mais tenra idade encontram-se muitas vezes em sofrimento psíquico, experimentando pressão e ansiedade. Por outro lado, mesmo em casos em que o estado de sofrimento é mais grave, as crianças, de maneira geral, não se sentem ou não se identificam como doentes. Por si sós, elas não vão se submeter aos rigores de uma terapia (Klein, 1975, 1997; Sigal, 2002). Aqui, cabe aos responsáveis pela criança olhar para ela e, ao identificarem que algo não vai bem, que alguma coisa está atrapalhando seu bom desenvolvimento e o processo de maturação, procurar a ajuda de um profissional especializado. Dessa forma, como a criança só chega à clínica e retorna a ela por meio de algum adulto que se preocupe e se dedique a cuidar dela, para que o tratamento seja realizado, é necessário que se estabeleça um vínculo de confiança entre o terapeuta e os responsáveis pelo paciente. Devido a essa relação de dependência da criança em relação aos pais, estes acabam invariavelmente sendo inseridos no espaço analítico (Dolto, 1971, 1984; Klein, 1975, 1997; Sigal, 2002).

Realizado o primeiro momento de escuta da queixa dos pais ou responsáveis, cabe ao terapeuta avaliar se esta se enquadra na área de trabalho da clínica com crianças. Winnicott $(1986,2005)$ situa como campo sobre o qual recai o nosso fazer os distúrbios que não apresentam causa orgânica, mas, sim, psicológica, sendo, portanto, um obstáculo ao processo maturacional e ao desenvolvimento emocional do indivíduo. Assim, os distúrbios psicológicos acarretam imaturidade emocional para o sujeito, uma vez que há uma falha na capacidade do self de se relacionar com as pessoas e com o ambiente. Segundo Winnicott $(1986,2005)$, a psicoterapia se propõe a eliminar esse obstáculo, devolvendo o sujeito ao processo de desenvolvimento e maturação. Para tanto, a modalidade de atendimento clínico que a psicoterapia vai adotar - o tipo de manejo despendido pelo terapeuta para com seu paciente - vai depender da especificidade do caso e das necessidades do paciente, visto que a técnica da psicanálise apresenta grande diferença conforme o paciente possuir uma organização neurótica, psicótica ou antissocial (Winnicott, 1979, 1983).

Independentemente do tipo de sofrimento apresentado, a clínica com crianças possui especificidades que a distinguem do fazer da clínica com adultos, a saber, que a criança expressa suas fantasias, desejos, experiências e conflitos de uma forma indireta, isto é, de um modo simbólico através do brincar. Nesse sentido, seria função do terapeuta dentro do setting interpretar o significado e compreender o conteúdo daquilo que a criança está querendo lhe comunicar (Klein, 1975, 1997). Contudo, o que realmente importa ao paciente não é a precisão da interpretação, mas, sim, o desejo do terapeuta em ajudá-lo e a capacidade deste de se identificar com a criança e, assim, satisfazer as suas necessidades logo que estas sejam transmitidas verbalmente ou em linguagem não verbal ou pré-verbal. Assim, se o terapeuta consegue ser objetivo e se preocupar com as demandas da criança, então o tratamento será bem-sucedido em se adaptar às necessidades do paciente conforme estas se apresentarem ao longo do atendimento (Prebianchi, 2011; Winnicott, 1979, 1983).

Contudo, para que as interpretações e os novos insights oferecidos ao paciente sejam gradualmente aceitos, faz-se necessário um ambiente suficientemente amparador e tolerante com os aspectos infantis, sejam eles perversos, conflitantes, agressivos ou estranhos. Tal ambiente constitui o holding do tratamento. Os pacientes, ao passo que vão se apropriando da complexidade que envolve o trabalho analítico, vão identificando na pessoa do analista uma postura de interesse e disposição de ajudá-los a refletir acerca de seus sentimentos e comportamentos. Da atitude do terapeuta os pacientes obtêm um forte sentimento de confiança tanto no tratamento quando na própria figura do profissional, visto que se percebem enquanto lembrados e reconhecidos nas suas singularidades. Embora, ao longo de todo o atendimento, a criança fantasie sobre a ameaça e a possibilidade de perda dessa relação devido a constantes ataques à pessoa do analista, ao manter sua presença e interesse pelas questões do paciente, o terapeuta mostra que sobrevive às explosões deste e não o retalia por isso, nutrindo-o de uma sensação de constância e amparo - o holding - que possibilita que a criança se sinta segura em terapia e permitindo que o trabalho interpretativo e o processo analítico se deem (Sandler, 2001). Aqui, o que faz a especificidade do trabalho clínico é a receptividade do terapeuta, a sua capacidade de "escuta" (Dolto, 1979, 2004).

Com o intuito de levantar em que sentido têm se dado as pesquisas no campo da clínica infantil, realizouse uma busca na base de dados em Psicologia da Biblioteca Virtual em Saúde (BVS). Foram utilizados os descritores "psicoterapia da criança" e "psicoterapia infantil" para encontrar textos completos em português e, 
selecionaram-se os que se encontravam indexados ao Periódicos Eletrônicos em Psicologia (Pepsic) e ao $\mathrm{Sci}$ entific Electronic Library Online (SciELO). Desse modo, foram localizados 29 artigos científicos relacionados à psicoterapia com crianças, o que evidencia uma escassez de estudos nessa área (Deakin \& Nunes, 2008, 2009). Destaca-se que os artigos mais recentes encontrados se referem a práticas em clínicasescolas (Amaral et al., 2012; Maturano, Silvares, \& Oliveira, 2014; Prebianchi, 2011). Foi encontrado apenas um artigo que versa sobre a representação que o infante tem de psicoterapia (Polli \& Arpini, 2013) e nenhum que trata da representação de psicólogo pela criança ou no qual a criança fala de sua experiência em psicoterapia.

A partir disso, levanta-se a importância de se realizarem estudos que ouçam a criança enquanto paciente de psicoterapia e indivíduo que tem muito a expressar sobre si, devendo ela ser o foco de novas investigações que visem compreender a forma como as crianças vivenciam e experimentam as diversas estratégias terapêuticas nos diferentes contextos em que estas se dão. Tal aspecto ganha maior relevância quando se destaca que as crianças constituem a clientela que mais busca, mais recebe e mais abandona os tratamentos nas clínicas de Psicologia (Cunha \& Benetti, 2009). Levando isso em consideração, o presente trabalho buscou investigar como crianças que estavam em atendimento psicológico na rede básica de saúde representam o seu terapeuta.

\section{MÉTODO}

\section{Desenho do estudo}

Com o intuito de alcançar o objetivo proposto, foi realizado um estudo qualitativo. Segundo Creswell (2007), uma abordagem qualitativa geralmente é realizada quando o pesquisador entende que para o fenômeno ou conceito estudado existem diversas e variadas significações e representações. Desse modo, o investigador tenta alcançar a complexidade dessa experiência a fim de desenvolver uma teoria ou tema, cuja elaboração ocorre a partir da coleta, análise e interpretação dos dados - sejam eles textos ou imagens - que emergem dos participantes do estudo. O pesquisador, assim, estabelece significados para o fenômeno investigado a partir da visão dos participantes.

Com relação ao contexto, o presente estudo foi realizado em uma Unidade Básica de Saúde (UBS) de uma cidade de porte médio do interior do Rio Grande do
Sul. A referida UBS localiza-se na zona norte da cidade, a qual compreende 18 vilas. Essa região caracterizase por altos índices de desemprego e criminalidade, baixo nível de escolaridade, e habitação e saneamento básico precários. Na UBS, são desenvolvidas diversas ações de saúde em atenção básica voltadas para adultos, adolescentes e crianças que habitam a região.

\section{Participantes}

Para a execução deste estudo, investigou-se a representação de psicoterapeuta de oito crianças com idade entre cinco e 12 anos incompletos que realizaram atendimento psicológico em instituição pública de saúde. Com relação ao número de sujeitos participantes, este foi definido em função do critério de saturação (Fontanella, Ricas, \& Turato, 2008). As crianças que integraram o estudo realizaram atendimento psicológico de orientação psicanalítica por pelo menos cinco meses no serviço de Psicologia da referida UBS. Tal serviço era prestado pelo curso de Psicologia de uma instituição federal de ensino superior e desenvolvido por seus acadêmicos, sob a supervisão de professores e técnicos dessa instituição. De maneira geral, as sessões eram realizadas com frequência semanal, mas alguns casos eram atendidos duas vezes por semana. Ao longo do ano de terapia, a criança era atendida pelo mesmo estagiário e, caso fosse indicada a continuidade do tratamento, mudando-se o ano, mudava-se também o terapeuta. Todas as crianças integrantes do estudo tiveram experiência de atendimento com terapeutas do sexo feminino. Com relação à demanda, as crianças foram encaminhadas para tratamento por diferentes motivos, a saber: a) agitação excessiva e baixo rendimento escolar; b) sobrepeso; c) agressividade e desobediência; d) briga com os colegas e agitação na escola; e) tristeza; f) dificuldade de aprendizagem e gagueira; g) tristeza e agressividade; $h$ ) agitação e agressividade.

\section{Instrumentos}

Para a apreensão da maneira como as crianças representam o seu terapeuta, utilizou-se o desenho-estória (D-E). Conforme Trinca e Tardivo (2002), o D-E constitui uma técnica composta por desenhos livres seguidos de narrativas de estórias também de modo livre. Técnica que possibilita à criança comunicar-se livremente pelo uso da projeção e da associação livre, o D-E é aplicado individualmente, necessitando apenas de folhas de papel brancas, lápis preto e de cor. A tarefa é iniciada com o pesquisador solicitando à criança que faça um desenho. Ela, em seguida, é estimulada a contar uma estória a ele. Após a realização do desenho e a 
contação da estória, o pesquisador, durante o inquérito, pode fazer perguntas com o objetivo de buscar mais detalhes e/ou esclarecer certos pontos do material produzido pela criança. Por fim, é pedido um título para a estória e é guardado o desenho. Esse procedimento é repetido mais algumas vezes, dependendo do objetivo da pesquisa. Ao término do D-E, o investigador ainda deve tomar nota de como o indivíduo se comportou durante toda a aplicação.

Para este estudo, foi solicitada uma sequência de três D-E relacionados com a temática da clínica infantil, a saber: 1) o desenho da sala onde a criança é atendida; 2) o desenho da criança na terapia; e 3) o desenho do terapeuta da criança. O procedimento do desenhoestória com tema é o mesmo do D-E, com a única diferença de que é solicitada a produção de desenhos e, consequentemente, de estórias com determinado tema (Trinca \& Tardivo, 2002). Todas as aplicações do desenho-estória foram realizadas pelo autor do presente artigo.

\section{Coleta de dados}

A coleta de dados iniciou-se com a criança fazendo o desenho da sala onde ela era atendida. Em seguida, ela foi solicitada a escrever uma estória sobre esse primeiro desenho, a qual, depois, foi lida ao pesquisador. Caso a criança não soubesse escrever, o pesquisador escreveu a estória para a criança, a qual, portanto, teve que contá-la ao pesquisador. Após a estória ter sido narrada, o investigador leu a estória para a criança, verificando se era aquilo que ela queria contar ou se havia mais algo que ela gostaria de acrescentar. Durante o inquérito, o pesquisador fez perguntas com o intuito de esclarecer pontos relacionados ao desenho e à estória, como, por exemplo, o que a criança havia desenhado. Por último, pediu-se a ela que desse um título à estória. Esta e o desenho, então, foram, por fim, guardados. O procedimento foi repetido mais duas vezes, com a solicitação do desenho da sala onde a criança era atendida e do seu terapeuta.

\section{Análise dos dados}

A avaliação dos dados foi feita através de análise de conteúdo (Bardin, 1977). Num primeiro momento, a sequência de desenho-estória de cada criança foi analisada separadamente, sendo avaliado o que havia aparecido em cada D-E. Posteriormente, foi realizada uma análise de todas as crianças conjuntamente, focalizadose o que aparecia com maior intensidade e frequência, portanto, o que era comum e se repetia nos desenhos e nas estórias. Através da análise dos dados coletados pelo D-E foram estabelecidas as categorias a serem trabalhadas. Utilizou-se a teoria psicanalítica como referencial para a realização da discussão dos resultados, buscando, com isso, uma compreensão de como a criança que realizou atendimento psicológico em instituição pública de saúde representa o seu psicoterapeuta.

\section{Aspectos éticos}

O presente estudo foi submetido e aprovado pelo Comitê de Ética em Pesquisa da instituição de ensino superior local, sob o registro 0259.0.243.000-10, respeitando as regulamentações vigentes em pesquisas que envolvem seres humanos. Buscando manter o anonimato das crianças, o material apresentado por cada uma foi identificado através de um número, do sexo $(\mathrm{M}-$ masculino; $\mathrm{F}$ - feminino) e da idade da criança (exemplo: criança 1, F, 9 anos).

\section{RESULTADOS E DISCUSSÃO}

As crianças que participaram do estudo representaram sua psicóloga enquanto alguém que "brincava comigo" (criança 4, M, 11 anos). Nesse sentido, a terapeuta foi percebida como uma pessoa que desenhava, pintava e jogava junto com a criança, como mostram as seguintes falas: "O que eu mais gostava de fazer era brincar. Mais de Banco Imobiliário. E a minha psicóloga, de brincar comigo" (criança 3, M, 9 anos); "Ela [a sala] é legal. Eu e a terapeuta sempre desenhemo, joguemo, eu ganho dela no jogo de carta. (...) Eu sempre brinco com a psicóloga" (criança 1, F, 9 anos). Destaca-se aqui que o terapeuta joga junto com a criança, pois é através do brincar - no espaço compartilhado de jogo - que o psicólogo muitas vezes consegue atuar dentro do setting terapêutico, seja interpretando, seja intervindo de outra maneira (Winnicott, 1971, 1984). Esse atributo do terapeuta enquanto alguém que "joga comigo" (criança 2, F, 11 anos) pôde ser inferido no desenho (figura 1) e nas estórias a seguir:

Quando eu ia lá a gente fazia tudo que era legal. A sala é bonita, grande, verde claro. Tinha brinquedo pra mim brinca com ela. Tinha uns carro grande de controle remoto pra gente brinca e eu pechei com ele na parede uma vez (criança 4, M, 11 anos).

Nós tava lá conversando, eu tava dando tchau pra ela, já tava na hora de ir embora. Aí chegou o outro dia. Aí nós começamos a brincar de novo, conversar, escrever, brincar de dominó, brincar com boneca, brincar com os ursinhos, jogar UNO, jogar pife. Eu gosto de jogar pife (criança 7, F, 6 anos).

Além de brincar, a figura do psicólogo ainda foi vi- 


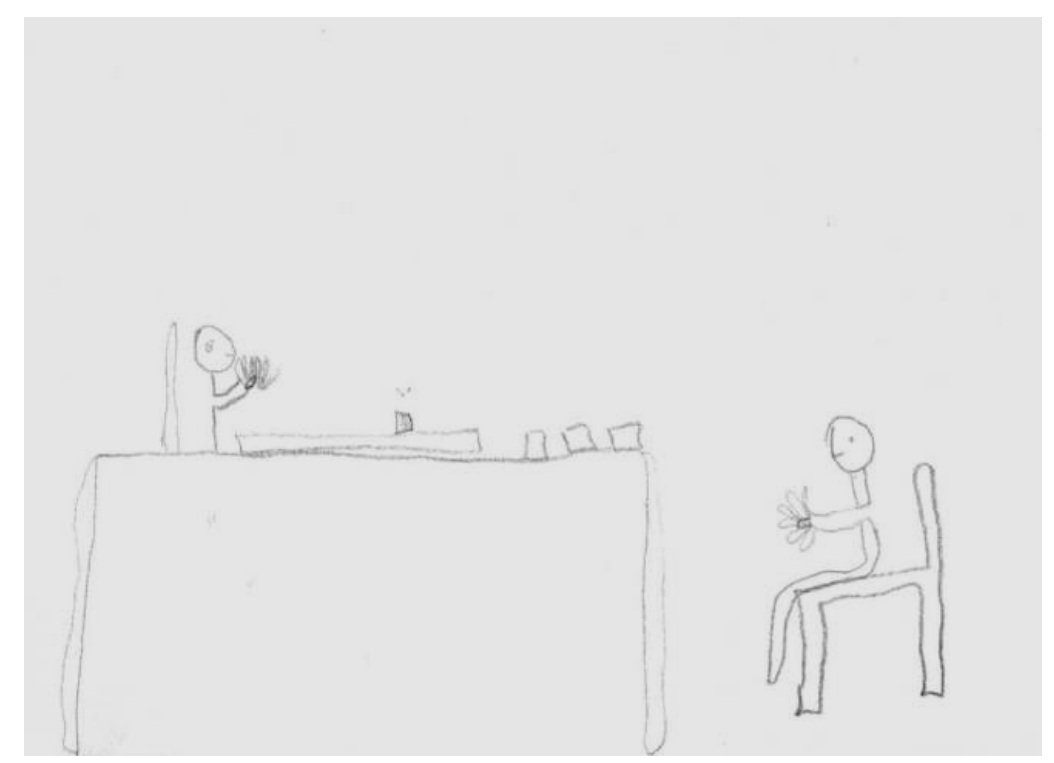

Figura 1. Criança 2, F, 11 anos. Desenhou a si mesma e a psicóloga sentadas à mesa, jogando pife.

venciada pelas crianças como alguém que "conversa comigo" (criança 5, F, 5 anos). Nesse sentido, a terapeuta foi percebida como alguém que "fala muito bonito" (criança 5, F, 5 anos), "sempre me escuta as coisas que eu preciso falar" e "me pergunta algumas coisas e eu respondo" (criança 1, F, 9 anos). Tal destaque dado ao conversar também foi apontado pela criança 2 (F, 11 anos), a qual disse que "nós conversamos muito também. (...) Ela [a psicóloga] é bem legal, enquanto nós estávamos jogando nós conversávamos bastante". Tal aspecto atribuído ao terapeuta também se fez presente na estória a seguir:

Lá era legal ela conversava coisas legais como: como eu era e ela era; conversava das brincadeiras; etc. Ela falava também do colegio. Eu gostava de i lá porquê ajente brincava conversava desenhava e ela conversava com minha mãe. Ela dizia que ia no colégio, mas eu achei que ela não ia. Ela dezenho comigo várias coisas (criança 4, M, 11 anos).

$\mathrm{O}$ destaque que as crianças que integraram o estudo deram para a figura do terapeuta enquanto alguém que joga e conversa com elas aponta para o reconhecimento, por parte dos pacientes, dos dispositivos dos quais o psicólogo se utiliza para ajudá-los a trabalhar suas questões. Seja através do brincar ou da fala - ou ainda da escuta -, o terapeuta acompanha a criança em suas atividades desenvolvidas por esta dentro do setting terapêutico, operando enquanto suporte para as experiências dela de exploração e elaboração ao longo do tratamento. Assim, o profissional figurou como alguém com participação ativa nas iniciativas e atividades realizadas por seus pacientes, senda esta uma maneira privi- legiada de entrar em contato e se comunicar com o mundo interno da criança (Felice, 2003).

Ao dizer sobre si, seja pelo brincar, seja pela fala, o paciente está evidenciando que confia no seu psicólogo para apresentar e compartilhar suas questões e problemas. Desse modo, para que o processo terapêutico se dê, é fundamental que a criança estabeleça com o seu terapeuta um vínculo de confiança para que possa se sentir à vontade para trazer-lhe suas associações, medos, fantasias, pensamentos e sentimentos, ou seja, toda uma gama de informações pessoais sem as quais o profissional não teria material para realizar suas interpretações e intervenções e, com isso, empreender um tratamento junto à criança (Klein, 1975, 1997). É nesse sentido que o trabalho do terapeuta deve objetivar, dentre outras coisas, fornecer um ambiente confiável e acolhedor no qual o paciente possa trazer, através da transferência, seus conflitos inconscientes, torná-los conscientes e elaborá-los de maneira imaginativa (Winnicott, 1971, 1984). De acordo com Dolto (1971, 1984, 1998), é através da transferência que a criança deposita no seu psicólogo o sentimento de confiança que opera enquanto base das intervenções terapêuticas. É devido a esse fenômeno que o paciente consegue, com tanta facilidade, trabalhar imaginativamente durante o tratamento, compartilhar o seu mundo interior e contar sonhos e segredos que não comunica a mais ninguém.

Para tanto, o psicólogo deve manter em sigilo qualquer pormenor do tratamento, não transmitindo aos pais ou responsáveis do paciente nada que a criança tenha 
lhe confiado, tendo esta o mesmo direito à discrição do terapeuta que um adulto tem (Klein, 1975, 1997). Tal vínculo de confiança pôde ser apreendido do seguinte desenho (figura 2), no qual a criança se desenhou "indo pra sala de braços abertos porque eu vou dar um abraço na minha psicóloga" (criança 8, F, 6 anos), evidenciando na criança a crença de que esta poderia se "jogar" e se "entregar" à terapia e ao terapeuta, acreditando que seria amparada e acolhida.
A importância do sigilo para a relação terapeuta-paciente também foi constatada nos D-E através da valorização que as crianças deram ao fato de a psicóloga não contar para ninguém as coisas que elas trouxeram durante o atendimento. Pode-se pensar o quanto esse aspecto possibilitou a construção da relação de confiança (Deakin \& Nunes, 2008), a qual permitiu ao infante trazer e comunicar os seus segredos para a sua psicóloga, visto que, ao estabelecer um setting seguro e

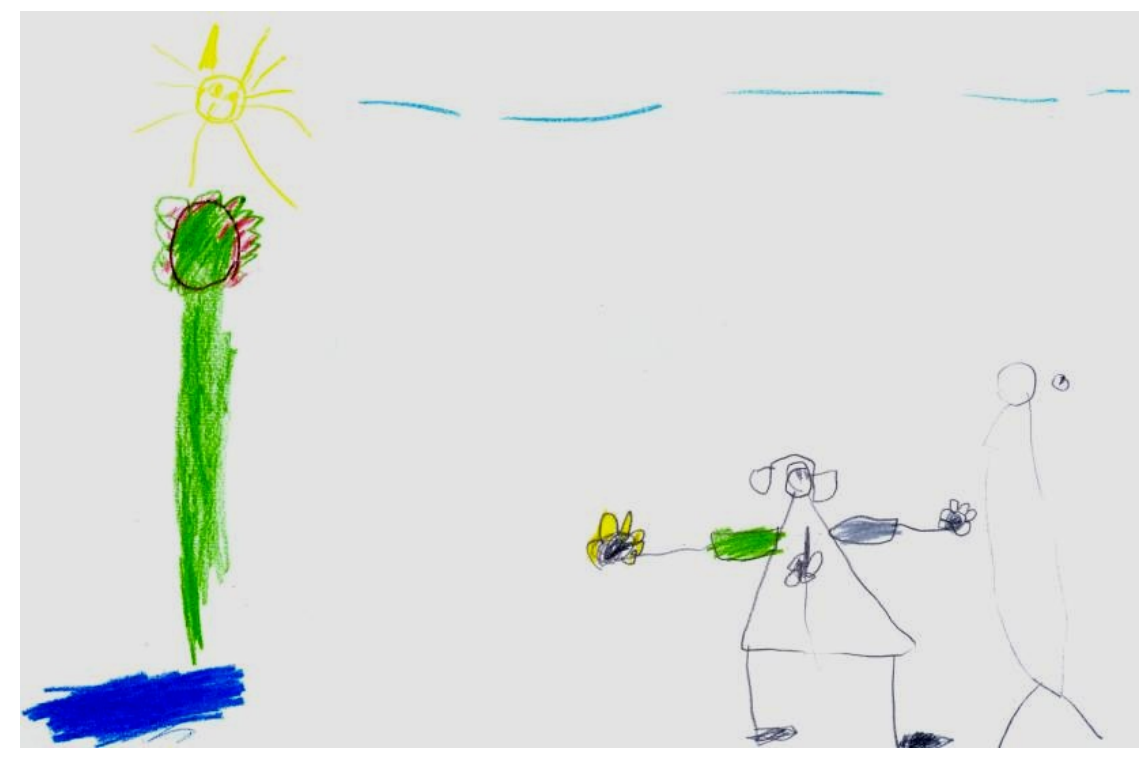

Figura 2. Criança 8, F, 6 anos. Desenhou a si mesma de trancinha. Na roupa um girassol bicudo, uma árvore com maçãs, sol, mar de brincar de pelúcia e nuvens. Ao seu lado, a primeira tentativa de se ilustrar, da qual desistiu.

protetor, o profissional está criando as bases para a formação do vínculo terapêutico com o seu paciente (Marques \& Arruda, 2007). Esse ponto ficou evidente no discurso das crianças, quando elas disseram: "Eu falo as coisas pra ela, ela não fala pra minha mãe. Eu falo os meus segredos pra ela" (criança 1, F, 9 anos), e na estória a seguir:

Só eu e a psicóloga que sabemos [o segredo]. A vó não sabe. (...) Gosto também de conversar com ela na sala. E ela me fala que eu posso falar pra ela que ela não vai falar pra ninguém. E eu acho muito bom. Eu acho que ela não conta mesmo (criança 5, F, 5 anos).

Tendo em vista a relevância da qualidade da relação estabelecida entre profissional e paciente para o tratamento, a terapia foi experienciada enquanto um ambiente aonde vão "eu e a minha psicóloga. Ninguém mais" (criança 3, M, 9 anos), isto é, um tempo na semana que a criança tem só para abordar as suas questões com a sua terapeuta, um espaço onde profissional e paciente trabalham juntos, de acordo com os desejos e as necessidades da criança. Nesse sentido, era o infante, por ser o paciente, que dava o rumo do que acontecia durante as sessões: "Eu escolhia as coisas que a gente ia fazer. (...) Ela [a psicóloga] brincava. Brincava de qualquer jogo. Eu perguntava se ela queria jogar esse jogo e ela dizia que "sim"” (criança 3, M, 9 anos); "A gente pode brincar de qualquer coisa e ela [a terapeuta] gosta de fazer as coisas que eu gosto" (criança 5, F, 5 anos).

Embora o tratamento tenha sido representado por algumas das crianças como esse ambiente aonde vão, "só eu e ela [a psicóloga]" (criança 6, M, 5 anos), ou seja, um lugar destinado apenas para a relação terapeuta-paciente, outras pessoas que frequentavam o mesmo espaço ao longo de todo o tratamento também se fizeram presentes nos desenhos-estórias. A criança 3 (M, 9 anos), ao falar que, além dela, outras crianças também eram atendidas na sala de atendimento psicológico infantil, relatou que "primeiro era eu, depois era outra [criança]. Ela [a terapeuta] fazia com elas a mesma coisa que ela fazia comigo". Por sua vez, a criança 7 (F, 6 
anos) contou que à sala ia "só eu. E umas outras pessoas. Aí tinha que esperar um pouquinho. Não sei quem eram ou o que faziam lá". Essas frases apontam para uma atividade, presente nos pacientes, de indagar-se sobre outras pessoas que a sua terapeuta vê e recebe no seu consultório. Pode-se inferir que esse questionamento acontece na medida em que a criança percebe que, além dela, outras crianças também são atendidas por sua psicóloga, uma vez que essa criança vê outros meninos e meninas entrando e saindo da sala de sua terapeuta antes e depois de cada uma das suas sessões de psicoterapia.

Além das outras crianças atendidas pelo Serviço de Psicologia, os familiares responsáveis pelo atendimento também receberam destaque nos D-E produzidos pelos participantes do estudo. Quando perguntada sobre quem frequentava a sala de atendimento, a criança 5 (F, 5 anos) disse: "A minha vó, o meu vô e a minha mãe. E eu. A psicóloga fala com a vó os horários que eu tenho que ir lá. O vô e a mãe esperam por mim". A fala da criança 7 (F, 6 anos), quando comenta que: "quem me trazia era a minha vó. A minha mãe não podia me trazer", aponta o quanto, para essas crianças, o adulto entra no processo de psicoterapia como alguém responsável por levá-las ao atendimento e saber os dias e horários que elas deveriam comparecer. Assim, os pais e avós figuraram como os responsáveis pela ida da criança às sessões. Isso se justifica pelo fato de que as crianças, mesmo as que estão em sofrimento psíquico muito grave, geralmente não se identificam como doentes, só chegando à terapia por intermédio de algum adulto responsável que se preocupe com a saúde da criança e que perceba que alguma coisa está atrapalhando o seu desenvolvimento. Devido a essa relação de dependência de seus cuidadores, estes - sejam eles pais, tios ou avós - acabam invariavelmente sendo inseridos no campo terapêutico (Deakin \& Nunes, 2009; Dolto, 1971, 1984; Finkel, 2009; Klein, 1975, 1997; Prebianchi, 2011; Sei, Souza, \& Arruda, 2008; Sigal, 2002). Essa inserção dos familiares na terapia das crianças também foi destacada no desenho a seguir (figura 3):

Contudo, as sessões de devolução e orientação feitas com os responsáveis pelos infantes no tratamento deixaram as crianças com dúvidas sobre o que é conversado entre terapeuta e seus pais/avós durante esses encontros. A criança 1 (F, 9 anos), após ter falado que a sua mãe também ia às vezes à sala de atendimento, relatou não saber o que a mãe fazia lá: "Não sei. A mãe não me conta. Não, eu sei. A mãe e a psicóloga conversam. A psicóloga conta as coisas que eu falo pra minha

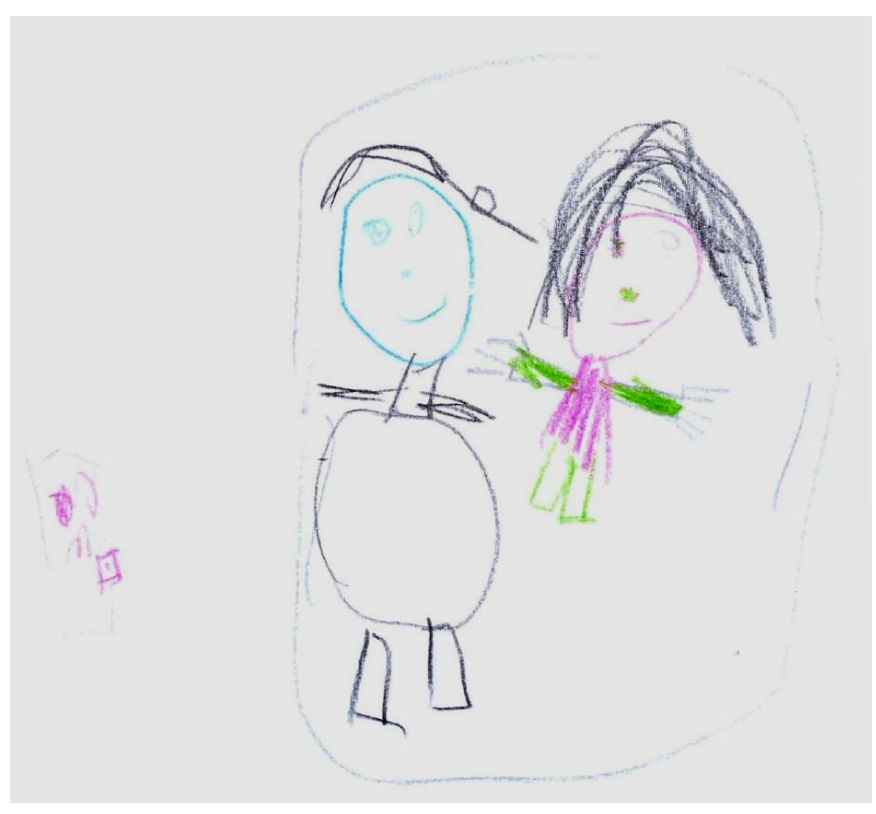

Figura 3. Criança 5, F, 5 anos. Desenhou a si mesma e a avó num banco, esperando a terapeuta chamar, e a porta da sala.

mãe". Indo ao encontro da ideia apresentada pela criança 1 , a criança 4 (M, 11 anos), após ser indagada sobre o que a mãe e a psicóloga conversavam, disse: "Ah, isso tu vai ter que perguntar pra minha mãe. Eu não sei. Nunca me contaram. Acho que conversavam em como foi lá dentro, o que que a gente fez". Tais falas apontam para um desconhecimento, por parte do paciente, sobre o que era falado quando seus responsáveis iam conversar com a psicóloga. Dessa forma, mesmo se tendo evidenciado que as crianças tinham uma relação de confiança com suas terapeutas, podem surgir incertezas e fantasias sobre o que pais/avós e psicóloga fazem na sala, incluindo até a suspeita de quebra do sigilo por parte da terapeuta, a qual pode vir a contar para os cuidadores o que a criança havia confidenciado apenas a ela em segredo. Tais sentimentos se fazem presentes em razão desse "desconhecido", visto que as crianças não estão juntas nas sessões de devolução e orientação.

Apesar disso, as crianças representaram a sua terapeuta como uma pessoa "legal, fofa, querida" (criança 1, F, 9 anos), "bem bonita", que "gosta de mim" (criança 7, F, 6 anos) e de quem "Eu gosto (...). Eu gosto da psicóloga" (criança 5, F, 5 anos). A partir dessas falas e de outros aspectos apreendidos durante a aplicação do D-E - a criança 3 (M, 9 anos) refez o desenho da psicóloga três vezes -, evidenciou-se uma valorização que as crianças fizeram de suas terapeutas. Pode-se inferir que tal valorização se deve à importância que a figura do psicólogo teve para elas ao longo do tempo em que 
estiveram em atendimento, visto que o terapeuta opera enquanto um ego auxiliar que possibilita ao paciente reviver experiências traumáticas conforme as suas capacidades (Boarati, Sei, \& Arruda, 2009). Tal importância também pode residir no fato de que "ela [a psicóloga] me ajudava" (criança 3, M, 9 anos), tendo em vista que o que realmente importa ao paciente é o desejo do terapeuta em auxiliá-lo e a capacidade deste de se identificar com a criança e, assim, atender às suas demandas logo que estas lhe são transmitidas (Winnicott, 1979, 1983). Desse modo, os infantes vão identificando na pessoa do profissional uma postura de interesse e disposição de ajudá-los a refletir acerca de seus sentimentos e comportamentos, obtendo dessa atitude um forte sentimento de confiança tanto no processo terapêutico quando na própria figura do terapeuta (Sandler, 2001).

Tendo em vista que um dos objetivos da terapia é tornar as crianças mais capazes de tolerar as frustrações e sofrimentos inerentes ao processo de viver, possibilitando que elas se adaptem melhor à realidade - mesmo que esta seja difícil - e enfrentem as dificuldades que a vida thes apresentar (Klein, 1975, 1997), algumas características foram atribuídas pelos infantes aos profissionais da Psicologia para que estes possam exercer seu papel. Nesse sentido, o terapeuta deve ter "o pé no chão" (criança 1, F, 9 anos), "dedos para brincar comigo" (criança 5, F, 5 anos) e:

(...) olhos para enxergar e ouvidos para escutar. Tem que escutar todas as minhas perguntas e todas as minhas historinhas, todas as minhas coisas. Ela tem que ter orelha para escutar tudo isso. Olhos para enxergar as coisas que a gente pode ver lá [na terapia]. Alguma coisa que esteja me incomodando que eu não saiba o que é (criança 5, F, 5 anos).

Tais falas denunciam que a psicóloga, para auxiliar os pacientes a abordar e trabalhar seus problemas e suas dificuldades, tem que estar totalmente dentro da sessão, com a sua atenção voltada para aquilo que a criança está tentando lhe dizer, seja através do brincar, seja por meio da fala. O terapeuta tem que estar interessado e engajado nessa complexa tarefa de acompanhar e amparar a criança ao longo de todo o percurso do tratamento, sendo necessários para isso uma escuta aguçada e um olhar diferenciado, próprios do fazer da Psicologia. Assim, é necessário que o profissional esteja atento ao que é enunciado pelo sintoma da criança, uma vez que só uma postura investigativa perante o sentido que o sintoma contém torna possível, por sua vez, uma postura analítica diante do sofrimento apresentado pelo paciente (Mannoni, 1967, 1987).

Interação Psicol., Curitiba, v. 20, n. 1, p. 69-80, jan./abr. 2016
Além disso, o destaque dado à figura do terapeuta pode ter ocorrido pela capacidade dele de criar um ambiente suficientemente amparador e tolerante aos aspectos infantis, por mais hostis ou estranhos que pareçam, ou seja, o holding do tratamento (Sandler, 2001). Nesse sentido, as crianças comentaram: "Eu converso com ela [a psicóloga] as coisas, ela me entende" (criança 2, F, 11 anos). Esse entender, antes de apontar para uma compreensão por parte da terapeuta, muito mais diz de uma característica do profissional da Psicologia em acolher o paciente, seus impulsos e suas demandas sem realizar julgamento moral ou reprovação de comportamentos e traços peculiares deste, muitas vezes vivenciados pela criança fora do espaço terapêutico. Por isso a psicóloga "era boa, não era braba" (criança 3, M, 9 anos), por não se mostrar contrária ou repreensiva com relação aos padrões de funcionamento, pensamentos e fantasias apresentados pela criança durante o atendimento. Aqui, conforme Dolto (1979, 2004), o que faz a especificidade do trabalho clínico é a receptividade do terapeuta, a sua capacidade de "escuta", aspecto que tem sido destacado também por outros autores (Meyer \& Berlinck, 2011; Prebianchi, 2011).

Nesse contexto, fez-se presente o medo de a terapeuta não resistir e, portanto, não sobreviver aos impulsos da criança, como destacado na fala da criança 3 (M, 9 anos): "Às vezes eu faltava quando tava chovendo. Às vezes ela faltava. Ela faltou só uma vez. Eu vim e ela não veio. Achei que ela não ia mais vir". Não se sabe como se deu o desencontro, mas a partir dele demonstra-se o receio de a criança perder essa pessoa tão importante para ela, que é a sua psicóloga. Embora seja comum e esperado que, ao longo de todo o tratamento, a criança fantasie sobre a possibilidade de perda dessa relação devido aos ataques realizados à pessoa do seu terapeuta, ao manter-se presente e interessado nas questões da criança, o psicólogo mostra que sobrevive às explosões desta e não a retalia por isso, propiciando e sustentando uma sensação de constância e amparo - o holding - que possibilita que a criança se sinta segura em terapia. Isso permite que o trabalho terapêutico se dê (Sandler, 2001). A valorização do lugar ocupado pela figura do terapeuta e dos papéis desempenhados por ele ainda pôde ser vista nesta fala: "A psicóloga me ouve. Ela é legal, querida e fofa. E ela me ouve, me escuta. Eu falo meus segredos" (criança 1, F, 9 anos) e nos desenhos a seguir (figuras 4 e 5):

Contudo, embora as crianças tenham demonstrado saber alguns dos atributos e funções exercidos pela psicóloga, ainda persistiu certa confusão quanto ao papel 


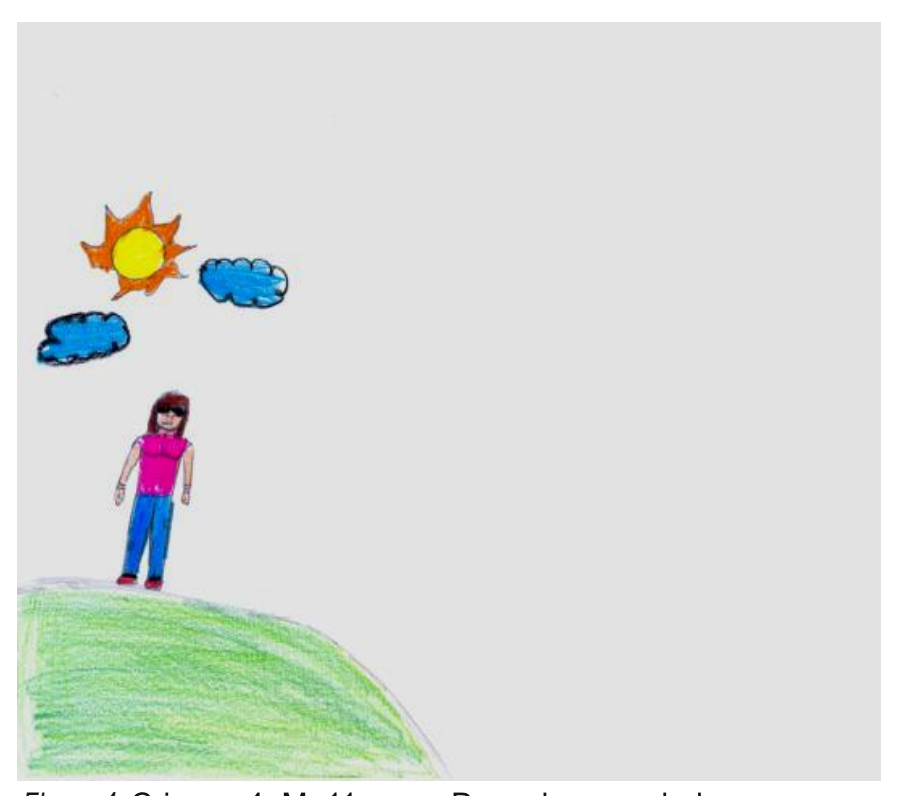

Figura 4. Criança 4, M, 11 anos. Desenhou o sol, duas nuvens, o chão com grama e a psicóloga.

desempenhado por ela, em relação a outras pessoas/profissionais. A criança 5 (F, 5 anos), durante a aplicação do D-E, disse que a psicóloga era amiga dela. Já a criança 8 (F, 6 anos), ao narrar a estória de um desenho em que se ilustrou junto com sua terapeuta, disse: "A minha professora tá contando uma história pra mim" (criança 8, F, 6 anos). Tal mistura de papéis pode se dar pelo fato de a criança, num período inicial da terapia, relacionar-se com a figura do terapeuta, que é nova para ela, a partir de modelos preexistentes. Por isso, pode-se pensar por que é tão comum a criança chamar o psicólogo de médico, doutor, professor ou tio, na busca de achar uma imagem que se encaixe no recorte desse novo profissional com quem agora entra em contato. A partir disso, pode-se inferir que o infante tenta atenuar a "estranheza" inerente ao contato com o novo carregando-o de sentido para torná-lo familiar e poder, com isso, relacionar-se com ele (Moscovici, 1978). Desse modo, evidencia-se que tal confusão de funções desempenhadas pelo terapeuta pode perdurar para além das sessões iniciais de terapia, sendo capaz de estender-se por meses, apontando para uma dificuldade, por parte da criança, de nomear e classificar o fazer e a especificidade do psicólogo clínico.

\section{CONSIDERAÇÕES FINAIS}

Através da aplicação da técnica do desenho-estória, pôde-se perceber que as crianças estudadas têm uma representação de psicoterapeuta enquanto alguém que brinca e conversa com elas. Nesse sentido, tanto o jogar quanto o falar/escutar figuraram como recursos utilizados pelo terapeuta para intervir e auxiliar a criança dentro do ambiente terapêutico. Lançando mão desses dispositivos, o terapeuta consegue acompanhá-la em suas atividades, funcionando como apoio para as experiências novas que a criança tem ao longo do tratamento.

Com relação ao processo terapêutico, para que este se dê é fundamental que a criança estabeleça com o seu terapeuta um vínculo de confiança, sendo necessário, para tanto, que o profissional forneça um ambiente acolhedor, no qual o paciente se sinta seguro para apresentar seus conflitos e elaborá-los. Para tanto, res-

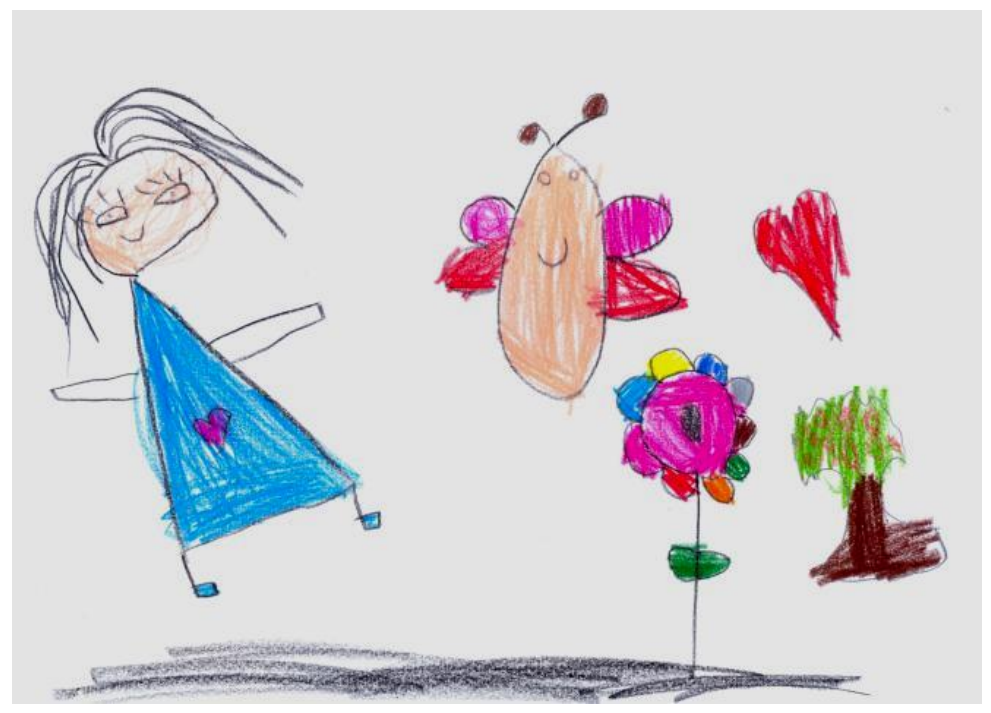

Figura 5. Criança 7, F, 6 anos. Desenhou a psicóloga com um coração na roupa, uma borboleta, uma flor, uma árvore com frutinhas, um coração e terra. 
salta-se a importância de o psicólogo manter em sigilo qualquer pormenor do tratamento, não transmitindo aos responsáveis da criança os conteúdos que esta lhe trouxer durante $o$ atendimento.

Além disso, a terapia foi vivenciada enquanto um ambiente destinado para à relação terapeuta-paciente, isto é, um lugar para a criança tem só para si e seu psicólogo trabalharem juntos as problemáticas daquela. Apesar disso, os infantes sinalizaram a presença de outras pessoas que também frequentavam esse espaço. Dentre elas, as outras crianças atendidas pelo seu terapeuta e os seus responsáveis. Com relação a estes últimos, as sessões de devolução e orientação que o terapeuta realiza com eles figuraram como momentos em que as crianças não têm certeza do que psicólogo e cuidadores conversam, surgindo a dúvida da possibilidade da quebra do sigilo. Nesse sentido, ressalta-se a necessidade de os profissionais terem uma atenção maior quando da realização desses encontros com os pais e avós, trabalhando, em sessão com as crianças, as fantasias delas sobre o que ocorre nos momentos de devolução.

Apesar disso, as crianças representaram a sua terapeuta como uma pessoa boa e legal, evidenciando-se uma valorização dessa figura. $\mathrm{O}$ motivo de tal valoração pode residir na importância que o psicólogo teve para essas crianças, uma vez que este as ajudou a explorar e a elaborar suas questões. Assim, para poder auxiliar seus pacientes, o terapeuta deve estar engajado na tarefa de acompanhar e ajudar a criança, estando atento ao que ela tenta lhe comunicar através do brincar e da fala. Além disso, o destaque dado à figura do terapeuta pode ter ocorrido por sua capacidade de criar um ambiente suficientemente amparador e tolerante aos aspectos infantis, o que aponta para a valorização dada pelas crianças ao holding recebido durante o tratamento. Neste contexto, fez-se presente o medo de a terapeuta não resistir aos impulsos hostis da criança, ressaltando-se, por isso, a necessidade de os psicólogos clínicos manteremse presentes e interessados nas questões do infante, "sobrevivendo" aos ataques que este thes dirige.

Destaca-se ainda a presença de certa confusão nas crianças quanto às funções desempenhadas pelo psicólogo. Aqui, salienta-se a importância de o profissional, percebendo a existência dessa "mistura" de papéis, auxiliar a criança, explicitando a especificidade do seu fazer. Nesse sentido, fantasias presentes na criança quanto a outras funções que o psicólogo poderia exercer que não dizem respeito à sua prática devem ser tra- balhadas durante o atendimento. Assim, acredita-se que, quanto mais claros forem, para a criança, o papel e a função do profissional da Psicologia, mais facilmente ela se apropriará das formas de se utilizar desse papel e dessa função durante o tratamento.

Por fim, como o presente trabalho teve como objetivo investigar a representação que crianças atendidas em psicoterapia em instituição pública de saúde têm do seu terapeuta, aqui cabem algumas ressalvas. À exceção da mudança de terapeuta - muito comum em atendimentos prestados por estagiários -, nenhum outro dado apontou para uma distinção significativa entre o atendimento clínico público e o privado. Sabe-se que diferenças existem entre ambos, uma vez que mudanças são necessárias para que o tratamento ofertado esteja adaptado à realidade de contexto e de clientela. Contudo, através dos resultados da pesquisa, destaca-se que tais alterações não foram tão evidentes a ponto de aparecerem nos dados coletados quando a intervenção em questão é a clínica infantil. Isso mostra que o fazer da Psicologia, embora o contexto mude, pode manter-se pautado nos mesmos princípios.

Além disso, pode-se pensar no quanto existem serviços de qualidade prestados no âmbito público, uma vez que a terapia foi representada pelas crianças como esta deve ser, independentemente do lugar em que ela se dá e das pessoas que ela atende, ou seja, um espaço destinado a realizar mudanças no paciente, com o intuito de este alcançar ganhos terapêuticos e melhorar. Não podemos, contudo, afirmar que todos os serviços de Psicologia prestados no setor público operam dessa forma. Por outro lado, os resultados evidenciam que isso é possível. Tal estudo também tem relevância, uma vez que a prática da Psicologia em serviços públicos de saúde tem se ampliado recentemente, tornando-se um espaço potencial enquanto campo de atuação da prática psicológica.

Apesar das importantes contribuições deste estudo para o campo da Psicologia Clínica com crianças, ressalta-se que ele apresenta limitações em função de seu recorte delineado pelo mesmo. É necessário levar em consideração que os achados dizem respeito ao contexto no qual esta pesquisa foi desenvolvida, não devendo ser feitas generalizações precipitadas para outras realidades. Por fim, destaca-se sua relevância, considerando a pouca produção de artigos que investigam o atendimento em psicoterapia de crianças em instituições públicas de saúde. Nesse sentido, sugere-se a realização de novas pesquisas para o fortalecimento da prática de 
psicoterapia com criança, em especial aquela que ocorre em serviços públicos de saúde.

\section{REFERÊNCIAS}

Amaral, A. E., Luca, L., Rodrigues, T. C., Leite, C. A., Lopes, F. L., \& Silva, M. A. (2012). Serviços de Psicologia em clínicas-escola: revisão da literatura. Boletim de Psicologia. 62(136), 37-52. Retirado de: http://pepsic.bvsalud.org/scielo.php?pid=S0006-59432012000100005\&scri $\mathrm{pt}=$ sci_arttext

Bardin, L. (1977). Análise de conteúdo. Lisboa: Edições 70.

Bezerra Jr., B. (1987). Considerações sobre terapêuticas ambulatoriais em saúde mental. In $\mathrm{S}$. A. Tundis \& N. R. Costa (Orgs.), Cidadania e loucura: políticas de saúde mental no Brasil (pp. 133-169). Petrópolis: Vozes.

Boarati, M. C. B., Sei, M. B., \& Arruda, S. L. S. (2009). Abuso sexual na infância: a vivência em um ambulatório de psicoterapia de crianças. Revista brasileira de crescimento e desenvolvimento humano, 19(3), 426-434. Retirado

http://pepsic.bvsalud.org/scielo.php?script=sci arttext\&pid=S0104-12822009000300008\&lng=es\&nrm=iso

Costa, J. B., Mombelli, M. A., \& Marcon, S. S. (2009). Avaliação do sofrimento psíquico da mãe acompanhante em alojamento conjunto pediátrico. Estudos de Psicologia (Campinas), 26(3). doi: 10.1590/S0103166X2009000300005

Creswell, J. W. (2007). Projeto de pesquisa: métodos qualitativo, quantitativo e misto. Porto Alegre: Artmed.

Cunha, T. R. S., \& Benetti, S. P. C. (2009). Caracterização da clientela infantil numa clínica-escola de psicologia. Boletim de psicologia, 59(130), 117-127. Retirado de http://pepsic.bvsalud.org/scielo.php?script=sci_arttext\&pid=S0006-59432009000100010

Deakin, E. K., \& Nunes, M. L. T. (2008). Investigação em psicoterapia com crianças: uma revisão. Revista de psiquiatria do Rio Grande do Sul, 30(1). doi: 10.1590/S0101-81082008000200003

Deakin, E. K., \& Nunes, M. L. T. (2009). Abandono de psicoterapia com crianças. Revista psiquiatria do Rio Grande do Sul, 31(3), 145-151. doi: 10.1590/S0101-81082009000300003

Dolto, F. (1984). Psicanálise e Pediatria - As grandes noções da Psicanálise - Dezesseis observações de crianças (A. Cabral, Trans.). $4^{\text {a }}$ ed. - Rio de Janeiro: Zahar Editores. (Trabalho original publicado em 1971)

Dolto, F. (1998). O limite de nossos poderes. In F. Dolto \& N. Hamad, Destinos de crianças: adoção, famílias de acolhimento, trabalho social (pp. 3-18) (E. Brandão, Trans.). São Paulo: Martins Fontes. (Trabalho original publicado em 1984)

Dolto, F. (2004). Prefácio. In M. Mannoni, A primeira entrevista em psicanálise: um clássico da psicanálise (pp. $7-$ 33) (R. C. Lacerda, Trans.). Nova ed. - Rio de Janeiro: Elsevier. (Trabalho original publicado em 1979)

Felice, E. M. (2003). O lugar do brincar na psicanálise de crianças. Psicologia: teoria e prática, 5(1), 71-79. Retirado de http://pepsic.bvsalud.org/scielo.php?pid=S151636872003000100006\&script $=$ sci_arttext
Figueiredo, A. C. (1997). Vastas confusões e atendimentos imperfeitos: a clínica psicanalítica no ambulatório público. Rio de Janeiro: Relume-Dumará.

Finkel, L. A. (2009). O lugar da mãe na psicoterapia da criança: uma experiência de atendimento psicológico na saúde pública. Psicologia: ciência e profissão, 29(1), 190-203. Retirado de http://pepsic.bvsalud.org/scielo.php?script $=$ sci arttext\&pid=S1414$98932009000100 \overline{0} 16$

Fontanella, B. J. B., Ricas, J., \& Turato, E. R. (2008). Amostragem por saturação em pesquisas qualitativas em saúde: contribuições teóricas. Cadernos de saúde pública, 24(1), 17-27. doi: 10.1590/S0102-311X2008000100003

Klein, M. (1997). A psicanálise de crianças. (Obras completas de Melanie Klein; v. II) (L. P. Chaves, Trans.). Rio de Janeiro: Imago Ed. (Trabalho original publicado em 1975)

Mannoni, M. (1987). A criança, sua "doença" e os outros: o sintoma e a palavra (A. C. Villaça, Trans.). $3^{\text {a }}$ Ed. - Rio de Janeiro: Guanabara. (Trabalho original publicado em 1967)

Marques, C. F. F. C., \& Arruda, S. L. S. (2007). Autismo infantil e vínculo terapêutico. Estudos de Psicologia (Campinas), 24(1), 115-124. doi: $10.1590 / \mathrm{S} 0103-166 \mathrm{X} 2007000100013$

Maturano, E. M., Silvares, E.F., \& Oliveira, M. S. (2014). Serviços-escola de psicologia: seu lugar no circuito de permuta do conhecimento. Temas de Psicologia, 22(2), 215. doi: 10.9788/TP2014.2-15

Menezes, M., López, M., \& Delvan, J. S. (2010). Psicoterapia de criança com alopecia areata universal: desenvolvendo a resiliência. Paidéia, 20(46). doi: 10.1590/S0103-863X2010000200013

Meyer, G. R., \& Berlinck, M. T. (2011). Um olhar singular: a clínica na instituição de saúde mental. Estilos da Clínica, 16(1), 152-169. doi: 10.11606/issn.19811624.v16i1p152-169

Moscovici, S. (1978). A representação social da psicanálise. Rio de Janeiro: Zahar Editores.

Polli, R. G., \& Arpini, D. M. (2013). Representação de psicoterapia em crianças atendidas em instituição de saúde. Psicologia em Estudo, 18(3), 519-528. doi: 10.1590/S1413-73722013000300013

Prebianchi, H. B. (2011). Atenção psicológica infantil: compreensão de usuários e estagiários do serviço-escola. Psicologia em Revista, 17(2), 322-339. doi: 10.5752/P.1678-9563.2011V17N2P322

Ropa, W., \& Duarte, L. F. D. (1985). Considerações teóricas sobre a questão do "atendimento psicológico" às classes trabalhadoras. In S. A. Figueira (Org.), Cultura da psicanálise (pp. 178-201). São Paulo: Editora Brasiliense.

Sandler, A. M. (2001). Sobre interpretação e holding na análise de crianças. In R. Grana \& A. B. S. Piva (Org.), A atualidade da psicanálise de crianças: perspectivas para um novo século (pp. 65-73). São Paulo: Casa do Psicólogo.

Sei, M. B., \& Cintra, M. F. V. (2013). Psicanálise de crianças: histórico e reflexões atuais. Revista da Universidade Ibirapuera, 5(1), 1-8. Retirado de http://www.revistaunib.com.br/vol5/PSICANALISE_DE_CRIANCAS_HIST 


\section{ORICO_REFLEVOES_ATUAIS.pdf}

Sei, M. B., Souza, C. G. P., \& Arruda, S. L. S. (2008). O sintoma da criança e a dinâmica familiar: orientação de pais na psicoterapia infantil. Vínculo, 5(2), 194-205. Retirado de http://pepsic.bvsalud.org/scielo.php?script=sci_arttext\&pid=S1806

24902008000200009\&lng=pt\&nrm=iso\&tlng=pt

Seixas, S. G. M. (2011). É possível haver a transferência analítica em uma instituição de saúde mental?. Estudos de psicanálise, Belo Horizonte, 35, 115-126. Retirado de http://pepsic.bvsalud.org/scielo.php?script=sci_arttext\&pid=S0100 34372011000200013\&lng=pt\&nrm=iso\&tlng=pt

Sigal, A. M. R. (2002). Psicanálise com crianças. A legitimidade de um campo. Os pais, o recalque e a circulação de significantes enigmáticos na condução da cura. In A. M. Sigal de R., O lugar dos pais na psicanálise de criança (pp. 27-43). São Paulo: Editora Escuta.

Trinca, W., \& Tardivo, L. (2002). Desenvolvimentos do processo de desenhos-estórias (D-E). In J. A. Cunha, Psicodiagnóstico - V (pp. 428-438). Porto Alegre: Artmed.
Winnicott, D. W. (1983). O ambiente e os processos de maturação: estudos sobre a teoria do desenvolvimento emocional (I. C. S. Ortiz, Trans.). Porto Alegre: Artmed. (Trabalho original publicado em 1979)

Winnicott, D. W. (1984). Consultas terapêuticas em psiquiatria infantil (J. M. X. Cunha, Trans.). Rio de Janeiro: Imago Ed. (Trabalho original publicado em 1971)

Winnicott, D. W. (2005). Tudo começa em casa (P. Sandler, Trans.). $4^{\mathrm{a}}$ ed. - São Paulo: Martins Fontes. - (Psicologia e pedagogia). (Trabalho original publicado em 1986) 